九州大学学術情報リポジトリ

Kyushu University Institutional Repository

\title{
Effects of Forest Stand Density on Human's Physiophychological Changes
}

An, Ki Wan

Faculty of Forest Resources and Landscape Architecture, Chonnam National University

Kim, Eun Il

Faculty of Forest Resources and Landscape Architecture, Chonnam National University

Joen, Kyun Soo

Division of Bio-Environmental Science, Wonkwang University

Setsu, Takao

Laboratory of Landscape Architecture, Division of Forest Ecosphere Sciences and

Management, Department of Forest and Forest Products Sciences, Faculty of Agriculture, Kyushu University

https://doi.org/10.5109/4588

出版情報：九州大学大学院農学研究院紀要. 49 (2)，pp. 283-291，2004-10-01. Faculty of Agriculture, Kyushu University

バージョン：

権利関係 : 


\title{
Effects of Forest Stand Density on Human's Physiopsychological Changes
}

\author{
Ki Wan AN ${ }^{1 *}$, Eun Il KIM', Kyun Soo JEON ${ }^{2}$ and Takao SETSU \\ Laboratory of Landscape Architecture, Division of Forest Ecosphere Sciences and Management, \\ Department of Forest and Forest Products Sciences, Faculty of Agriculture, \\ Kyushu University, Fukuoka 811-2415, Japan \\ (Received June 30, 2004 and accepted July 13, 2004)
}

\begin{abstract}
This study was carried out to investigate the influences of forest stand density on human's physiopsychological changes using electroencephalogram (EEG), pulse, profile of mood states (POMS), and semantic differential attitude (SDA) of testees. The stand density, defined as the percentage of tree crown area of a $10 \mathrm{~m} \times 10 \mathrm{~m}$ plot, was adjusted with computer simulation in order to obtain $30 \%, 50 \%, 70 \%$, and $100 \%$ of coniferous and broad-leaved forests, respectively. In order to reduce experimental errors of testees, all experiments were conducted in a laboratory where temperature, humidity, and noise levels were controlled. The results obtained showed that a greater stand density of the coniferous forest causes greater activity in the frontal brain, while a lower stand density produces relaxation in the brain. For the broad-leaved forest, the EEG was most active when the stand density was $100 \%$, and both brain activity and pulse rate were most stable at a stand density of $50 \%$.
\end{abstract}

\section{INTRODUCTION}

In 2002 , Korea's forest area was about 6.4 million ha, of which $28 \%$ ( 1.8 million ha) was artificial forest started in the early 1970's as the country`s part of new forest policy. Plantation forests could provide well ordered and systematic scenery, which could be modified into a variety of sceneries with various forest management techniques and working systems such as clear cutting, thinning, and brush cutting. The purpose of plantation forests was to create sustainable timber production, which was the objective of national forest policies in Korea. However, public perceptions of forests in recent years have focused on their recreational functions such as air cleaning, watershed conservation and stress release rather than timber production according to improvements in life standards due to economic development. In particular, demand for recreational forests have increased since the late 1980's after the introduction of various recreational facilities in forests such as recreational forests, forest bathing areas, and the establishment of legal and administrational systems. The criteria used for the introduction of facilities in forests have been forest quality and a desirable construction site. However, the establishment of a forest management plan is required to maximize forest benefits in terms of the users since the type and composition of forests are expected to impact physiopsychological effects on the users.

1 Faculty of Forest Resources and Landscape Architecture, Chonnam National University, Gwangju, 500-757, Korea. Institute of Agricultural Science \& Technology

2 Division of Bio-Environmental Science, Wonkwang University, Iksan, 570-749, Korea

* Corresponding author (E-mail: kiwan@chonnam.ac.kr) 
There are limited studies on the physiopsychological effects of forest stand composition and stand density. For example, Kim (1994) compared the physiopsychological influence of beech (Fagus crenata var. multinervis) forest in relation to various seasons. The author also tried to compare the physiopsychological effects of beech (Fagus crenata var. multinervis) and thuja (thuja orientalis L.) forests (Kim, 1995), and both prunus (Prunus serrulata var. spontanea) and sugi (Cryptomeria japonica) forests (Kim, 1997). Kim et al. (1996) showed differences in EEG depending on forest and grass landscapes. Although these studies have concentrated on the physiopsychological influences of forests, not much work has been done on the effects of stand density.

Therefore, this study was carried out to investigate the effects of stand density on humans" physiopsychological influences. The results of this study are expected to help in the development of higher quality recreational forest models for users.

\section{EXPERIMENTAL METHODS}

In order to simulate real forest stand density and to detect physiopsychological changes, testees were exposed to various sceneries with different levels of stand densities. Their EEG, pulse, POMS, and SDA were measured while they were exposed to those sceneries.

\section{Tools of characterizing different levels of stand densities}

The stand density was defined as the percentage of tree crown area in a $10 \mathrm{~m} \times 10 \mathrm{~m}$ plot. The stand densities chosen for coniferous and broad-leaved forests were $30 \%, 50 \%$, $70 \%$, and $100 \%$ (Figs. 1 and 2). Digital images of real forests were used to develop artificial simulations of stand densities. The locations and view points were adjusted using

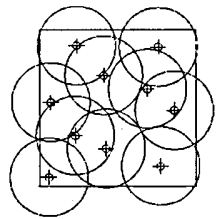

$100 \%$

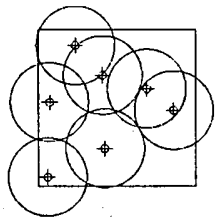

$70 \%$

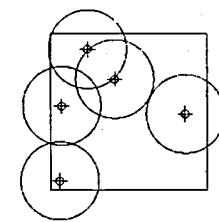

$50 \%$

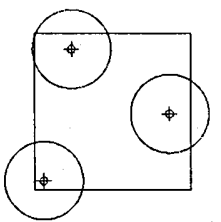

$30 \%$

Fig. 1. Tree locations of coniferous forests depending on their stand densities.

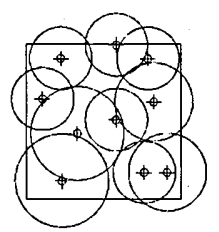

$100 \%$

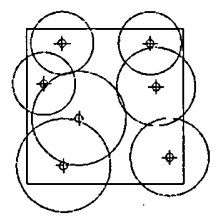

$70 \%$

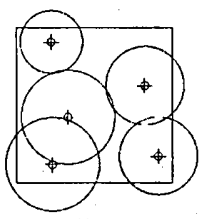

$50 \%$

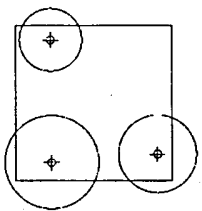

$30 \%$

Fig. 2. Tree locations of broad-leaved forests depending on their stand densities. 
computer software (Auto Cad and 3D Max), and image quality was controlled with Photoshop ver 7.0 software. Figs. 3 and 4 show different levels of artificial stand densities for coniferous and broad-leaved forests, respectively.

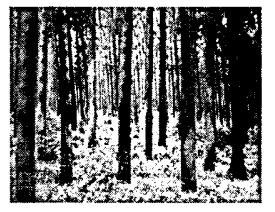

$100 \%$

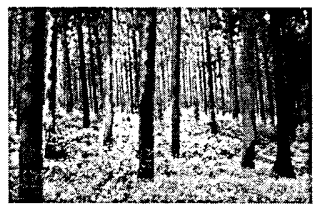

$70 \%$

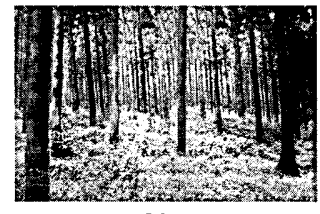

$30 \%$

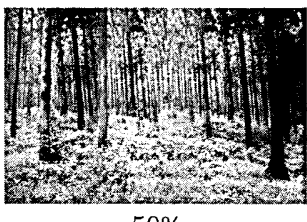

$50 \%$

Fig. 3. Stand density levels of coniferous forests.

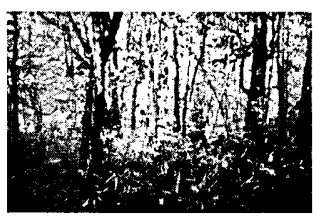

$100 \%$

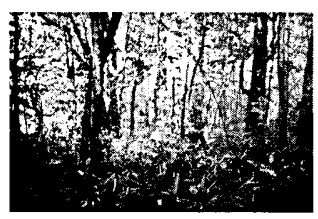

$70 \%$

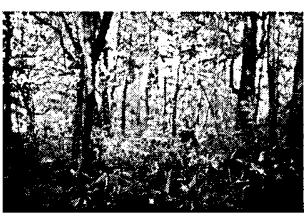

$30 \%$

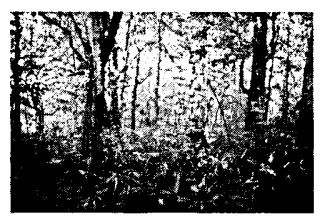

$50 \%$

Fig. 4. Stand density levels of broad-leaved forests.

\section{Experimental conditions}

It is very important to provide the testees with visual types under the same conditions. Thus, in order to reduce experimental errors between testee's physiopsychological states, all experiments were conducted in a laboratory, in which temperature, humidity, and external noises were controlled. The laboratory was also equipped with audio-visual systems such as a personal computer (PC), digital video display (DVD), and video display, which could simulate the intended environments for experiments (Fig. 5). The laboratory consisted of two rooms: a preparation room and an experimental room. Figs. 6 and 7 are pictures of a testee in preparation for during the actual experiment. This two-room system was used to minimize noise for testees in experiment, to reduce its influence on testee's results. All lights in the laboratory were turned off in order for testees to recognize images projected by the video display.

\section{Experimental procedures}

All experiments were conducted with the following procedures:

1. A testee sat down on a chair.

2. A sufficient explanation of the experiment was given in order to reduce the testee's level of anxiety, hesitation and fear.

3. Each sensor and equipment was put on the testee and checked. 


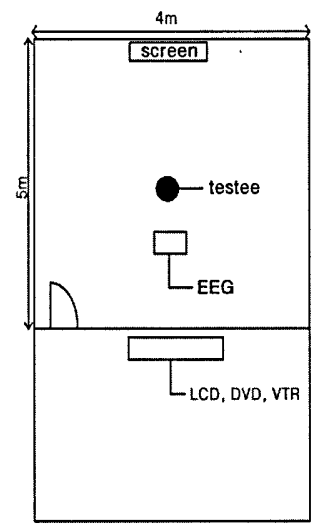

Fig. 5. Internal structure of the laboratory.

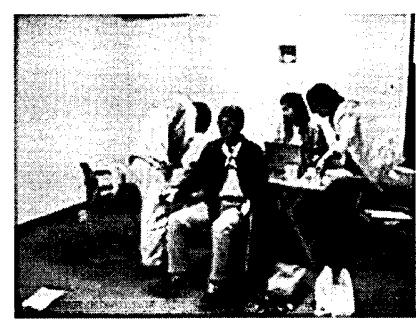

Fig. 6. A testee in preparation.

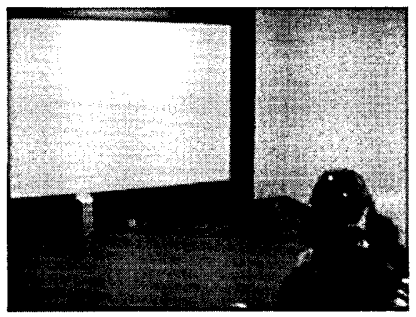

Fig. 7. A testee in experiment.

Table 1. Measuring items and times for each testee.

\begin{tabular}{c|c|c|c|c|c}
\hline Measuring item & \multicolumn{5}{|c}{ Procedures } \\
\cline { 1 - 3 } EEG & $\begin{array}{c}\text { Sensor set-up } \\
\text { and } \\
\text { Pulse }\end{array}$ & $\begin{array}{c}\text { Keep stable } \\
\text { state with } \\
\text { explanation of } \\
\text { expes closed } \\
\text { for 1 min. }\end{array}$ & $\begin{array}{c}\text { Data collection of } \\
\text { the first visual } \\
\text { type with eyes } \\
\text { opened for 1 min. }\end{array}$ & $\begin{array}{c}\text { Conduct the } \\
\text { POMS } \\
\text { and SDA }\end{array}$ & $\begin{array}{c}\text { Repeat the } \\
\text { experiment } \\
\text { with changing } \\
\text { the visual types }\end{array}$ \\
\hline
\end{tabular}

4. The experiment was conducted by exposing the testee to visual types.

5. EEG and pulse rate of the testee were recorded frist, and then POMS and SDA were measured under the same conditions (Table 1).

\section{Experimental methods}

In order to understand physiopsychological changes of testees depending on the levels of stand density, SDA and POMS were used to monitor their mood state. The EEG and pulse were recorded to understand the role of the brain and autonomic nervous system.

\section{Evaluation of semantic differential attitude}

The SDA was used for evaluation. A questionnaire that requires response in five steps to a pair of adjectives was distributed to selected testees after the experiment. Profile of Mood States (POMS)

The POMS, consisting of a questionnaire answered by the testee, measures the emotion and mood of a human depending on the exposed conditions. Sixty-five ques- 
tions used in the POMS were classified into 6 emotional levels such as distress-depression, vigor, anger-animosity, fatigues, and tension-anxiety. A score was assigned to each level, and the total score was calculated and used for comparison.

Pulse

The pulse was monitored as an indicator of the activity of the autonomic nervous system using the MP100 system (Biopac, Canada). The pulse rate of a testee measured one minute after exposure to a visual type was compared.

$E E G$

The EEG was measured by following the international 10-20 method with 10 electrodes (F3, F4, C3, C4, P3, P4, O3, O4, Fz and Pz). Active electrodes (A1 and A2) were used at a preauricular point while an indifference electrode was used following the method of unipolar lead.

The EEG was recorded using Cap electrodes (Electro-Cap International Inc., USA), which were connected to the MP100 system. In this study, the EEG used $\beta$ wave of greater than $13 \mathrm{~Hz}$ for interpretation as this wave was influenced by outside signals and general living activities. The EEG was captured in five seconds when a testee showed the strongest intensity while in contact with a visual type. The interpretation of recorded results was based on the normalized average value of each electrode.

\section{Testee and experiment time}

The testees exposed to this experiment ranged from 19 to 23 years old university students. The experiment was conducted over 6 days, from December 15 to 23, 2003.

\section{RESULTS AND DISCUSSION}

\section{EEG}

As shown in Fig. 8 , the $\beta$ wave at frontal, parietal, and occipital regions was most intensive when testees were exposed to the $100 \%$ stand density of coniferous forest, while it decreased at the 30\% stand density of coniferous forest. All EEG showed greater values at the $100 \%$ stand density. It was believed that these results were caused due to an increased activity of $\beta$ wave at greater stand densities. In contrast, all EEG decreased at the $30 \%$ stand density, which indicated less brain activity.

As shown in Fig. 9, the $\beta$ wave was most intensive at the frontal and occipital regions, when testees were exposed to the $100 \%$ stand density of coniferous forest, while it was the least at the $50 \%$ stand density of coniferous forest. These results were believed to be due to the stable emotion of testees with lower intensity of the $\beta$ wave.

Pulse

The influence of stand density on pulse rate is shown in Figs. 10 and 11. In the case of coniferous forest, the pulse rate was the lowest at the $30 \%$ stand density, and was similar to the $50 \%$ stand density. However, there were dramatic changes between $50 \%$ and $70 \%$ stand density. In the case of broad-leaved forest, the pulse rate was low at the $50 \%$ stand density. As a result, it was judged that a lower stand density of coniferous forest provides emotional stability. In contrast, the $50 \%$ stand density of broad-leaved forest produced the lowest pulse rate. Thus, it was believed that the $50 \%$ stand density was best for providing emotional stability. However, the greatest pulse rate was found at 

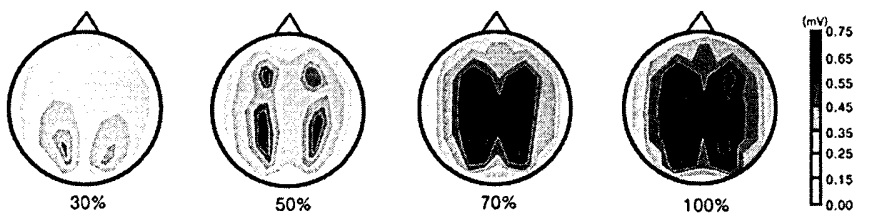

Fig. 8. The EEG profiles at different levels of stand density of coniferous forest and its scale.
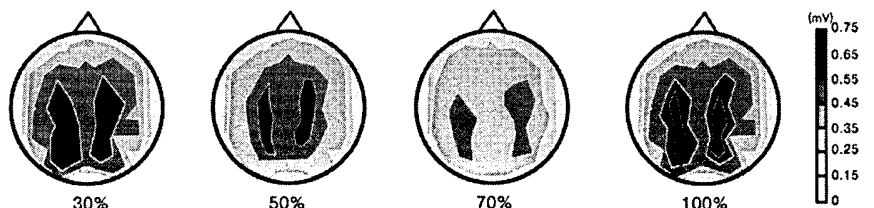

Fig. 9. The EEG profiles at different levels of stand density of broad-leaved forest and its scale.

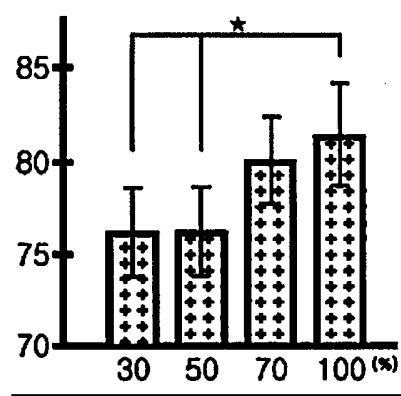

Fig. 10. Pulse rates depending on the stand density of coniferous forest.

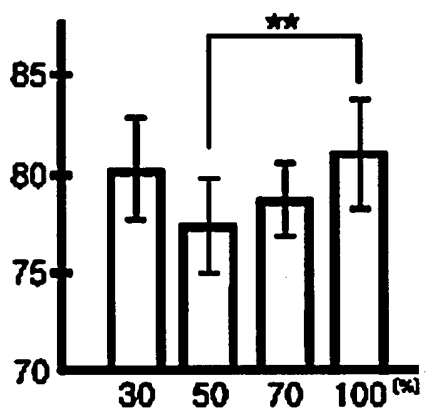

Fig. 11. Pulse rates depending on the stand density of broad-leaved forest.

the $100 \%$ stand density of both coniferous and broad forests. This result suggested that a greater stand density makes testees feel a little dark and depressed, which is recognized as an object of tension and fear.

\section{Test of POMS}

Figs. 12 and 13 show the results of POMS from both coniferous and broad-leaved forests. When testees were exposed to the coniferous forest, there were measurable changes for both "fatigues" and "tension-anxiety". The "tension-anxiety" mood was greatest for the $100 \%$ stand density with statistical significance $(p<0.05)$. This result 


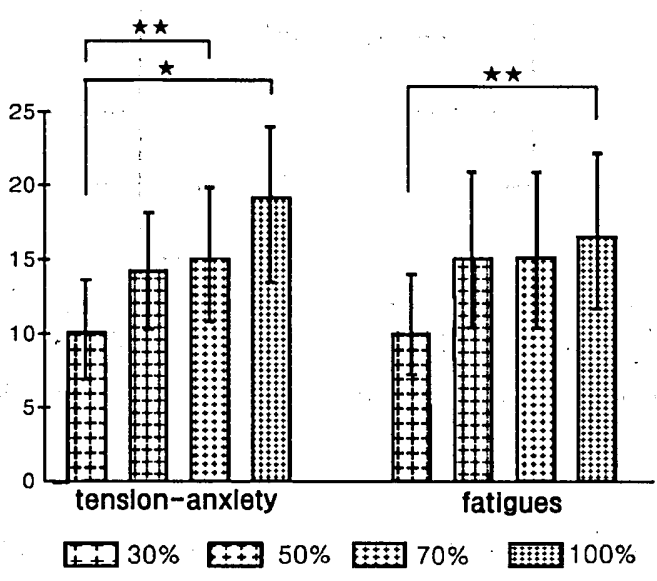

Fig. 12. POMS results at different levels of the stand density of coniferous forest.

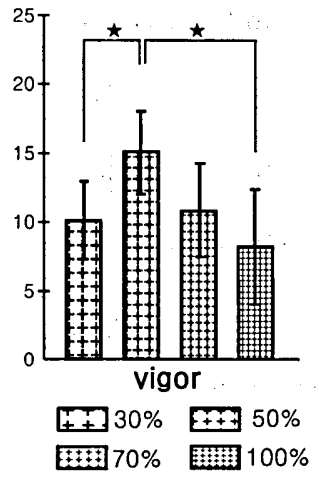

Fig. 13. POMS results at different levels of the stand density of broad-leaved forest.

suggested that testees experience tension and anxious states at the $100 \%$ stand density, which makes them fatigued. In contrast, a lower stand density of coniferous forest causes more emotional stability and less fatigue.

As shown in Fig. 13, "vigor" was different depending on the levels of stand density of broad-leaved forest. The highest "vigor" mood was observed at the $50 \%$ stand density of broad-leaved forest with statistical significance $(p<0.05)$. This result was believed to be due to a stable crown structure of broad-leaved forest, which could have brought spatial stability and "vigor" mood to testees exposed. However, the testees showed less "vigor" at the $30 \%$ stand density than that at the $70 \%$ stand density. This result suggested that widely open space at a lower stand density of broad-leaved forest could reduce the "vigor" mood of the testee. These results indicated that the profiles and spatial differences of forest stands bring psychological changes in the users.

\section{SDA}

Figs. 14 and 15 shows the results of factor analysis in order to understand the
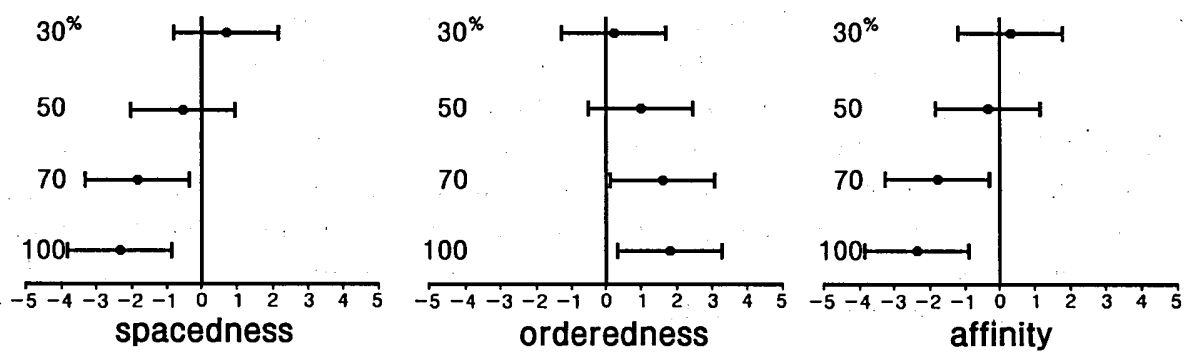

Fig. 14. Results of factor analysis of the coniferous forest with different levels of stand densities. 


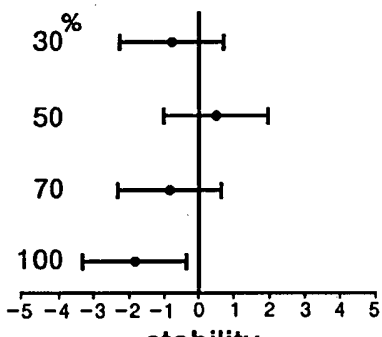

stability

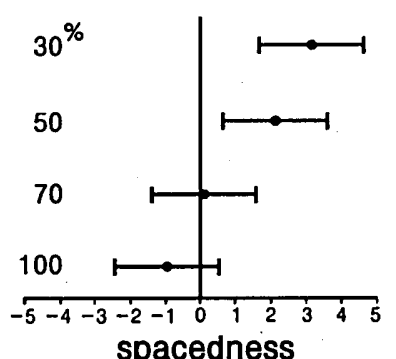

spacedness

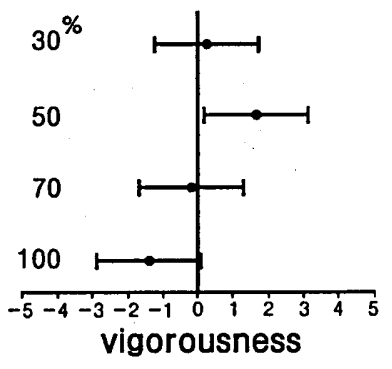

Fig. 15. Results of factor analysis of the broad-leaved forest with different levels of stand densities.

attitude of testees in relation to stand density images of both forests. As shown in Fig. 14, three aspects, including "spacedness", "orderedness" and "affinity" to the images of stand densities of coniferous forests were used to obtain scores. The "spacedness" score-that a testee felt enough space in the images of a stand density-was greatest at the $30 \%$ stand density. The "orderedness" score-that the testee felt well-ordered space in the images of a stand density-was greatest at the $100 \%$ stand density. The "affinity" score was greatest at the $30 \%$ stand density. All of these scores were statistically significant at a $p$-value of 0.01 . These results suggested that the $30 \%$ stand density gives spacedness while the $100 \%$ stand density provides orderedness to testees with reduced spacedness and affinity.

Fig. 15 shows the scores of "stability", "spacedness" and "vigorousness" of broad-leaved forest depending on the levels of stand density. The scores of "stability", "spacedness" and "vigorousness" were greater at the 50\%, 30\% and 50\% stand density, and were statistically significant at a $p$-value of 0.01 . However, the $100 \%$ stand density resulted in the lowest scores of "stability" and "vigorousness" due to very limited spaces. This result was quite contrary to the general belief that a greater stand density was more stable than a lower one.

\section{CONCLUSIONS}

This study was conducted to investigate the effects of forest stand density on humans physiopsychological changes and to develop a model of managing forests with optimum recreation. The results obtained were summarized as follows:

1. For coniferous forest, the EEG showed greater frontal brain activity at greater stand densities while it decreased at lower stand densities. The pulse rate was lower at the $30 \%$ and $50 \%$ stand densities, indicating a release of psychological depression. The results of the POMS showed increased tension and fatigue at the 100\% stand density, and these were reduced with decreasing stand density. The results of the SDA test indicated that the $30 \%$ stand density gave "spacedness" and "affinity" while "orderedness" increased with increasing stand density.

2. For broad-leaved forest, the EEG result did not show a gradual increase in stand 
density. However, the EEG was greatest and most stable at the $100 \%$ and $50 \%$ stand density, respectively. The results of POMS also showed that emotional stability and spacedness were found at the $50 \%$ and $30 \%$ stand density, respectively.

Therefore, a lower stand density of the coniferous forest provides the testee with spacedness and affinity, which results in a reduction of tension, anxiety, and fatigue due to the relaxation of brain activity. In contrast, the $50 \%$ stand density of broad-leaved forest produces the most stable mood and active vigorousness, which results in psychological stability due to brain relaxation.

\section{ACKNOWLEDGEMENTS}

This work was supported by grant No. R05-2002-000-01046-0 from the Basic Research Program of the Korea Science \& Engineering Foundation.

\section{REFERENCES}

Kim, E. I. and E. Fujii 1993 A Comparison of the Eye Movements to Natural and Artificial Tree Forms: Comparison between Korean and Japanese Men. Tech. Bull. Fac. Hort. Chiba Univ., 47: 165-170

Kim, E. I 1994 Comparison of physiopsychological effects of beech forests at green or red leaves stages. Korean Institute of Traditional Landscape Architecture, 12(2): 1-6

Kim, E. I., T. G. Song. K. W. An and T. Mitsuru 1996 A Foundational Study of Physiopsychological Effects of Forest or Grass land Landscapes by using Electroencephalogram. 14(2): 145-154

Kim, E. I. and E. Fujii 1995 A Fundamenntal Study of Physiopsychological Effects of the Color of Plant. J. JILA, 58(5): 141-146

Kim, E. I. and E. Fujii 1997 A study on visuopsychological effect of green space. Proceedings of IUFRO symposium in Kyoto

Kim, E. I., E. Fujii and T. Ando 1994 The Relations of the Eye Movement and the Electroencephalogram to the Color of Plant. J. JILA, 57(5): 139-144 